\title{
Need for Sustainability and Coexistence with Wildlife in a Compact City
}

\author{
Yukichika Kawata
}

\begin{abstract}
Recently, the underuse of wildlife and the increase in wildlife population due to decreased hunting have led to serious problems in both rural and urban areas. Traditional conservation methods are no longer applicable in such situations. The main purpose of this paper is, therefore, to explore ways to cope with increases in wildlife population and related issues, especially in urban areas. First, we present an overview of the current status of wildlife in urban areas, and examine why wildlife appears in cities. Then, after reviewing current expectations from compact cities through a comparison of Japan and western countries, we examine additional requirements for compact cities and depict possible future visions. Currently, the main objectives in establishing compact cities are sustainability and the prevention of population decline in local cities. We assert that when current cities are transformed into compact cities, consideration should be given to returning some space to wildlife whose habitats were altered when the cities were developed. We affirm that it is possible to ensure some space for wildlife. One possible use of reclaimed areas is as wildlife corridors, which should be distinguished from green space for residents. Former vegetation should be restored and continuous corridors secured, with recognition of the value of wildlife.
\end{abstract}

Index Terms-Compact city, coexistence, conflict, underuse, urban wildlife.

\section{INTRODUCTION}

Vegetation in rural areas is often at risk of damage by wildlife, especially in regions where wildlife habitats and human residence areas are close to each other or overlap. This problem has existed from the time human beings started developing agriculture and pastoral farming. Wildlife interference in human areas and the ensuing damage have been mitigated over the years by setting up nets, stone walls, electrified fences, etc. Humans have also hunted wildlife to reduce their numbers and to deter their interference. It is often in rural areas that such conflicts between wildlife and humans occur.

Often, we view the damage caused by wildlife in a human-centric manner. In ancient times, when human beings were not the dominant members of their ecosystem, they and other wildlife invaded and preyed upon one another. This mutual relationship started to change as agriculture and pastoral farming developed; human beings gradually replaced this mutual relationship with a human-centered relationship, i.e., they arranged everything for their own convenience. Human-wildlife conflicts of the current type began when people started to impose human-centered relationships with wildlife.

The next stage involved overexploitation of wildlife and loss of habitats caused by human beings, after which the wildlife population declined and some species went extinct. Eventually, human beings reconsidered their persecution of wildlife and introduced conservation activities. The promotion of conservation by humans indicates that the extent of human activities in ecosystems has become substantial. This implies that although human beings have established successful human-centered relationships with wildlife, it is sometimes impossible to maintain sound ecosystems without human intervention.

Recently, however, new problems, which are difficult to solve using traditional conservation methods, have emerged. Traditional conservation methods, which are mainly aimed at managing the overexploitation of wildlife, have been applied in rural areas. However, in some countries, including Japan, increases in wildlife population are attributed to a decrease in hunting and this is often seen as a serious problem. It is believed that this problem is a result of the underuse of wildlife, which happens in rural as well as urban areas.

The purpose of this paper is to explore ways to cope with wildlife population increases and related issues, especially in urban areas. Currently, cities seek compactness and sustainability. Therefore, it is necessary to consider sustainable coexistence with wildlife as one of the requirements of a compact city. In this paper, we provide the blueprint for a future compact city that has the potential to realize a sustainable coexistence with wildlife.

There are a number of existing research efforts that address the relationship between wildlife and human beings. Recently, some researchers have proposed that human beings have a strong impact on the habitats, environment, and population sizes of wildlife communities, and as a result, some conflicts between wildlife and human beings occur. Based on this understanding, it is crucial for human beings to reconsider the condition of their societies and their intended or unintended influences on wildlife, for appropriate wildlife management. Such themes are studied intensively in a new branch of ecology called the 'human dimension.' This paper could be classified as research in this category. However, this research is different from most of the existing research mainly with respect to the following points: this research focuses on the problem of the underuse of wildlife, and we point out the necessity of modifying the current concept of a compact city for sustainable coexistence with wildlife.

\section{CURREnT Status OF URBAN WiLdLIFE}

Y. Kawata is with the Department of Animal and Food Hygiene, Obihiro University of Agriculture and Veterinary Medicine, Inada-cho, Obihiro, Hokkaido 080-8555, Japan (e-mail: ykawata@ obihiro.ac.jp).
There are two types of wildlife in urban areas. The first is 
the kind that settles in urban areas and called 'urban wildlife,' and the second consists of wildlife that occasionally appears in urban areas. In this study, we do not distinguish between these two types, and we refer to the issues associated with both types of wildlife as urban wildlife issues. Urbanized areas and their associated areas can be classified as urban, suburban, exurban, and rural [1], [2]. It is in urban and suburban areas where settled urban wildlife exists and/or occasional wildlife appearance occurs. For convenience, we refer to both urban and suburban areas as 'urban areas' in this paper.

TABLE I: EXAMPLES OF WILDLIFE-HUMAN CONFLICTS

\begin{tabular}{|c|c|c|}
\hline Date / Place & Incident & Source \\
\hline $\begin{array}{c}25 \text { Jan., } 2011 \\
\text { Sekisho Line, } \\
\text { Hokkaido } \\
\text { Railway } \\
\text { Company (JR } \\
\text { Hokkaido). }\end{array}$ & $\begin{array}{l}\text { A sika deer entered a railway track } \\
\text { and a goods train followed the sika } \\
\text { deer for } 10 \mathrm{~km} \text { for nearly } 1 \mathrm{~h} .\end{array}$ & $\begin{array}{l}\text { Yomiuri } \\
\text { newspaper } \\
\text { 25 Jan., } \\
2011\end{array}$ \\
\hline $\begin{array}{c}5 \text { July, } 2011 \\
\text { Moriyama city, } \\
\text { Shiga } \\
\text { Prefecture }\end{array}$ & $\begin{array}{l}\text { Japanese monkeys entered the library } \\
\text { of the Kawanishi primary school. }\end{array}$ & $\begin{array}{c}\text { Yomiuri } \\
\text { newspaper } \\
5 \text { July, } \\
2011\end{array}$ \\
\hline $\begin{array}{l}12 \text { Sept., } 2011 \\
\text { Gifu city, Gifu } \\
\text { Prefecture }\end{array}$ & Nine wild boars attacked a kei car. & $\begin{array}{c}\text { Yomiuri } \\
\text { newspaper } \\
12 \text { Sept., } \\
2011\end{array}$ \\
\hline $\begin{array}{l}27 \text { Oct., } 2011 \\
\text { Sapporo city, } \\
\text { Hokkaido }\end{array}$ & $\begin{array}{l}\text { A brown bear, about two meters tall, } \\
\text { appeared in an urban area. }\end{array}$ & $\begin{array}{c}\text { Yomiuri } \\
\text { newspaper } \\
28 \text { Oct., } \\
2011\end{array}$ \\
\hline 10 June, 2012 & $\begin{array}{l}\text { A train that collided with a Japanese } \\
\text { serow at around } 19 \text { o'clock in } \\
\text { Yamagata Prefecture collided with a } \\
\text { black bear at around 19:45 in Sendai } \\
\text { city, Miyagi Prefecture. }\end{array}$ & $\begin{array}{l}\text { Yomiuri } \\
\text { newspaper } \\
\text { 10 June, } \\
2012\end{array}$ \\
\hline $\begin{array}{c}25 \text { June, } 2012 \\
\text { Tozawa village, } \\
\text { Yamagata } \\
\text { Prefecture }\end{array}$ & $\begin{array}{l}\text { A black bear appeared on the } \\
\text { grounds of the Tozawa primary } \\
\text { school. }\end{array}$ & $\begin{array}{c}\text { Yomiuri } \\
\text { newspaper } \\
\text { 26 June, } \\
2012\end{array}$ \\
\hline $\begin{array}{l}3 \text { July, } 2012 \\
\text { Sapporo city, } \\
\text { Hokkaido }\end{array}$ & $\begin{array}{l}\text { A brown bear appeared near the } \\
\text { Hujinosawa primary school when } \\
\text { pupils were attending school. }\end{array}$ & $\begin{array}{c}\text { Sankei } \\
\text { newspaper } \\
20 \\
\text { August, } \\
2012 \\
\end{array}$ \\
\hline $\begin{array}{l}7 \text { July, } 2012 \\
\text { Sapporo city, } \\
\text { Hokkaido }\end{array}$ & $\begin{array}{l}\text { A brown bear appeared near an urban } \\
\text { tennis court. }\end{array}$ & $\begin{array}{c}\text { Sankei } \\
\text { newspaper } \\
20 \\
\text { August, } \\
2012\end{array}$ \\
\hline $\begin{array}{l}5 \text { Oct., } 2012 \\
\text { Nagano city, } \\
\text { Nagano } \\
\text { Prefecture } \\
\end{array}$ & $\begin{array}{l}\text { A black bear appeared on the train } \\
\text { tracks of the JR Nagano station. }\end{array}$ & $\begin{array}{c}\text { Mainichi } \\
\text { newspaper } \\
5 \text { Oct., } \\
2012 \\
\end{array}$ \\
\hline $\begin{array}{l}21 \text { Oct., } 2012 \\
\text { Sakuho village, } \\
\text { Nagano } \\
\text { Prefecture }\end{array}$ & $\begin{array}{l}\text { A black bear entered the grounds of a } \\
\text { playschool. }\end{array}$ & $\begin{array}{c}\text { All } \\
\text { Nippon } \\
\text { News } \\
\text { Network } \\
21 \text { Oct., } \\
2012\end{array}$ \\
\hline $\begin{array}{l}22 \text { Oct., } 2012 \\
\text { Sapporo city, } \\
\text { Hokkaido }\end{array}$ & $\begin{array}{l}\text { A sika deer ran around in a } \\
\text { residential area. }\end{array}$ & $\begin{array}{c}\text { Yomiuri } \\
\text { newspaper } \\
22 \text { Oct., } \\
2012\end{array}$ \\
\hline
\end{tabular}

Note 1) All information was broadcast through websites.

Note 2) This table is not an exhaustive enumeration of incidents during the period.

The above-mentioned phenomena of settled urban wildlife and occasional wildlife appearance could be related to two processes: urbanization and synurbization. Luniak [3] states that 'urbanization refers to changes in landscape (environment) caused by urban development' and 'synurbization denotes adjustment of wildlife populations to specific conditions of urban environment.' In the rest of this paper, we refer to urban wildlife that settles in urban areas over the long term as synurbic populations.

Researchers have been interested in urban wildlife for quite some time. For example, this issue was raised in the United States in the 1930s, and there was increasing interest in the 1960s [4]. It is expected that more than $65 \%$ of the world's population will live in urban areas by 2025 [5]. Therefore, in the future, interest in urban wildlife will continue to increase, and conflicts between wildlife and human beings will be more serious.

Wildlife appearances in human residential areas have been reported in Japan in both urban and rural areas, and reports of these incidents, especially in urban areas, are often broadcast. A recent distinctive tendency involves the appearance of wildlife in highly urbanized areas; these appearances happen often and heavily influence human society at times (see Table I). Some of the main reasons for wildlife appearances in highly urbanized areas, apart from urbanization and synurbization, include wildlife population increase due to the reduction in hunting, and increasing temperatures (reduction of snow accumulation). According to the 6th Baseline Survey on the Conservation of Natural Environment, habitats of bears, Japanese serows, sika deer, monkeys, wild boar, foxes, and raccoon dogs have expanded when comparing the results of a 2003 study with those conducted in 1978 [6].

As a result, in deteriorating mountainous areas in Japan, serious agricultural/forestry damage happens; this damage further deteriorates these areas. Large wildlife such as deer, monkeys, wild boar, and bears also appears in urban areas often (Table I). Furthermore, raccoon dogs and other smaller wildlife intrude into the imperial palace in Tokyo and the Osaka Castle, which are located in the most urbanized areas of Japan. In Nagasaki Airport, which is the first offshore airport in the world, airport services including landing and take-off have been affected by settled raccoon dogs since the mid-1990s. Various wildlife species (especially habitat generalists) also inhabit urban areas in other countries [7]. Recent studies have reviewed the current status of synurbic carnivore populations in urban areas [8] and there are many existing studies on this topic [9].

\section{BACKGROUND ON WILDLIFE APPEARANCES IN CitIES}

There are several possible reasons for the appearance and/or settlement of wildlife in urban areas. Cities were frequently established on fertile plains near bodies of water, as the cradle of civilization suggests. Water bodies such as streams, rivers, lakes, and wetlands are very important for various migratory species (e.g., medium and large mammals and birds) and corridor dwellers (e.g., small mammals, amphibians, and reptiles) [10]-[12]. It has been pointed out that wildlife such as Japanese deer and wolves inhabited the plains in ancient Japan. Various wildlife species, including those mentioned above, were forced to vacate the plains and move to mountainous areas because of human development activities. However, some favourable wildlife habitat 
characteristics may persist even in modern urban areas.

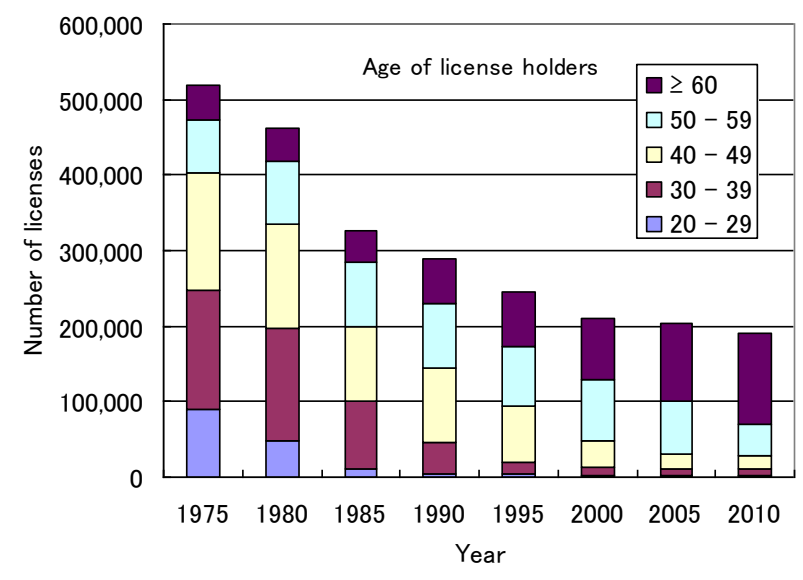

Fig. 1. The number of hunting license holders [13].

There are several additional reasons for wildlife inhabiting urban areas. First, wildlife likely settles in urban areas because the benefits exceed the costs because of the following two factors: The first factor is the improved physical accessibility to human areas. Until nearly half a century ago, human settlements and wildlife habitats were separated by clear buffer zones such as Satoyama (village forests), stone walls, and agricultural lands. However, the distance between the edges of urban areas and wildlife habitats (e.g., forests) have decreased because agricultural and forest lands have been developed adjacent to wildlife habitats. In some mountainous areas, agricultural and forest lands have reverted to cover (grasslands). Removal of buffer zones and the availability of cover make it easier for wildlife to invade human settlements.

The second factor is the improved psychological accessibility to human areas. Hunting has declined in Japan because of the advancing age of hunters, who have few successors among the younger generation (Fig. 1). Hunting is especially infrequent in those areas where new suburban areas and forests directly intersect. It is well known that once wildlife loses its fear of humans, it will act more boldly.

The second reason that wildlife inhabits urban areas is that such areas are beneficial to wildlife because they function as artificial covers. Urban areas generate a large amount of heat, and therefore urban microclimates are warmer than neighbouring regions, the results of which are milder winter climates and increased winter survival rates for wildlife. In addition, urban areas can function as sanctuaries for hunted animals because hunting is prohibited in cities. Several studies have reported that hunted animals diminish their home ranges during hunting season and/or escape into areas where hunting is prohibited [14], [15]. Further, some studies suggest that wildlife settlement in urban areas may result in a reduction in the transmission of wildlife parasites. However, other studies suggest that transmission may increase because of urban settlement (for more details, see, for example, Bradley and Altizer [2], which contains a detailed review).

Third, the availability of food in urban areas appears to have improved recently. Intentional feeding occurs in parks and open spaces in urban and suburban areas. Unintentional feeding also occurs because of inappropriate garbage management. Both of these feeding modes can be attributed to a lack of knowledge on interacting with wildlife. Traditionally, mainly rural citizens have faced conflicts between wildlife and human beings. However, in the future, urban citizens may be the chief victims of these conflicts. Under such circumstances, it will be necessary for us to understand the ecology of wildlife better.

In the following example, reported by Kogure [16], wildlife suffered losses because of human feeding. Racoon dog parents and their 10 leverets settled at the riverside of the Kurome River in Tokyo in 2000. They were gradually fed by onlookers. Normally, in autumn, the parents would have forced their kits to go to other places to become independent, but in this case, the parents moved to another place and the kits remained in the original location. Because of the rise of the water level in September, two kits died. This example indicates that feeding affects the ecology of raccoon dogs, and in this case, resulted in the death of two kits.

As the above description implies, the appearance of wildlife in urban areas may reflect their intention to return to their former habitats. The main purposes of a traditional compact city are, as we will review in the following section, to concentrate city functions in smaller areas and to increase the sustainability of urban areas. However, it is necessary to implicitly include in the purpose of a compact city the realisation of sustainable coexistence with wildlife. This is because wildlife habitats narrowed during the process of urbanization, and human ignorance leads to wildlife losses, as described above. Even now, habitats are being reduced because of the construction of roads and parking lots, resulting in traffic accidents involving wildlife.

\section{Current EXPECTATIONS From Compact Cities}

Some decades ago, urban areas experienced crime, congestion, and/or pollution. The development of a public transport system and a reduction in transportation costs made it possible to live more comfortably in suburban areas [17], [18]. Suburban living increases the dependence on vehicles and the associated emissions of greenhouse gases, and accelerates urban flight.

Howley [18] quotes Haughton and Hunter [19] and Gillham [20] when stating that in western countries, '[c]ompact city policies are designed to meet the primary sustainability aims of reducing car dependence and its concomitant pollution, and minimising the loss of open countryside and habitats to development.' There have been many important publications on this topic, including the Green Book on Urban Environment by the former European Council in 1990 and Rogers and Power [21].

The situation in Japan is somewhat different. After the relaxation of urban planning regulations in the 1990s, increased reliance on vehicles and construction of large commercial buildings in suburban areas occurred, and urban flight became a serious issue. The concepts behind compact cities have attracted attention because of their potential for rejuvenating denser areas in local cities and increasing economic efficiency [22].

The original idea of the compact city was proposed by Dantzig and Saaty [23], who discussed the efficient use of limited space in urban areas. Their ideas were subsequently 
developed in different directions, as mentioned above. They pursued the realisation of environmental sustainability, sustainable cities, and/or sustainable communities in western countries. On the other hand, they put more emphasis on rejuvenating denser areas in Japan.

Although the main objectives are different, commonalities exist: cities should be developed on a modest scale based on certain criteria. Emphasis is put on community development in Japan and on environmental sustainability in western countries. However, neither community development nor environmental sustainability alone is enough for the development of a successful compact city. It can be concluded that the difference between Japan and other countries is in their choice of emphasis.

\section{Additional ReQuirements For CoMPACt CitiES}

When current urban areas are transformed into compact cities (modest-scale cities), some areas should be restored as wildlife habitat. We altered wildlife habitats to develop these cities, and such restored areas would provide the minimum compensation needed. Possible uses of restored habitats may include wildlife corridors connecting existing wildlife habitats scattered throughout the city. Wildlife corridors in the centre of a city might be used by small animals and birds, whereas those closer to forests might be used by larger animals. The need for and efficiency of wildlife corridors have previously been discussed [24]-[26].

It is possible to ensure some space for wildlife. First, when reconstructing current cities into compact cities, some areas will be abandoned because the scale of the city will become smaller. Second, in compact cities, the number of cars will be reduced and fewer parking lots and roads will be required. Brown [27] stated that a million hectares of land have been transformed into roads and parking lots annually as the number of cars increased by 12 million. This trend could be reversed. Third, human populations in developed countries have peaked or even declined recently. If this trend continues, fewer residential areas will be required, and we can redevelop deteriorated areas into revitalised residential areas.

Wildlife corridors require certain conditions. Hostetler and Drakeb [26] indicated that it is important to explicitly distinguish between green spaces for humans and wildlife corridors when planning in urban areas. They also stated that it is essential to restore former vegetation when constructing wildlife corridors. Jim [28] states that '[t]he successful insertion of trees along many narrow pavements in Tokyo and other Japanese cities provides some hints for other compact cities.' As per the above assertions, however, there is much room for improvement in the current urban greening in Japan despite this positive statement.

The first step will require changes in perception. When we restore green space, we usually describe it as creating natural environments in urban areas. However, it should be thought of instead as restoration. It is necessary to examine which types of native vegetation and/or wildlife would return if we transformed potential open spaces into wildlife corridors. In addition, it is necessary to examine the layouts of wildlife corridors from the perspectives of wildlife and vegetation.
Currently, wildlife that wanders into urban areas has difficulty returning to its original habitats without a high risk of vehicle accidents. If we provide wildlife corridors that make it easier for wildlife to traverse the city, the coexistence of humans with wildlife may be more favourable.

In addition, there is a tendency for leftover spaces to be utilised as green space. Jim [28] states that '[d]ue to the intensive competition to use land, green spaces in compact areas tend to be small, isolated, and unevenly distributed, and are precious due to their scarcity.' One of the most desirable ideas might be a 'conservation subdivision' (cf. Hostetler and Drakeb [26] for details). It is difficult to ensure large spatially contiguous spaces in urban areas, particularly when planning sustainable cities through reconstruction of large cities. However, one of our main targets is local cities, especially in Japan, that experience population reductions. In such cases, it may be more realistic to plan large spaces in urban areas as wildlife corridors.

The National Spatial Strategy (MLIT [29]) was endorsed by the Cabinet of Japan in 2008. Based on this strategy, Japanese territories, excluding Hokkaido and Okinawa, were divided into eight large areas in which local strategies are being developed. The strategy requires the construction of ecological networks to conserve and restore the natural environment. Here, we have discussed the construction of wildlife corridors as one of the main requirements of a compact city. These concepts are consistent with the requirements of the National Spatial Strategy; wildlife corridors will help to ensure ecological network construction.

\section{RESEARCH PROSPECTS}

Currently, it might be less realistic to return parts of urban areas to wildlife. However, it will be eventually necessary to do so. In what follows, we introduce two ideas that will help in the realisation of sustainable coexistence with wildlife in urban areas.

As stated above, it is desirable to recover former vegetation. One of the most realistic ways is the utilisation of the Shinto shrines scattered around Japan (Fig. 2).

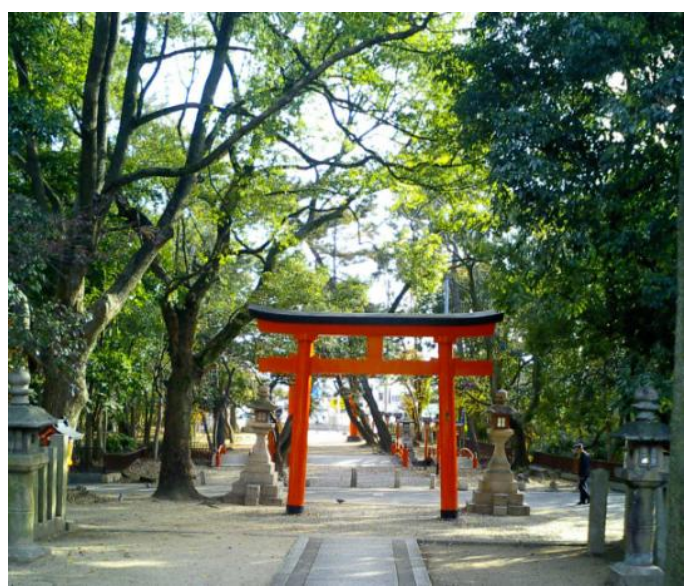

Fig. 2. Grounds of a Shinto shrine in an urban area

The total number of Shinto shrines is 81,285 [30]. Considering that most of these Shinto shrines have a few branches, the actual number of Shinto shrine buildings could be two to three hundred thousand. We have preserved the 
vegetation on the grounds of these shrines. In addition, because the shrine grounds are religious sanctuaries, they could function as sanctuaries for wildlife.

Next, our idea of including sustainable coexistence in the concept of a compact city implies closer relationships between wildlife and human beings. There could be varied scenarios. In some cases, habitats and/or corridors for wildlife (especially those for mammals) in urban areas are clearly separated from human residence areas, but in other cases, they overlap (especially in the case of some kinds of birds). It is important to separate these two types of areas to reduce possible conflicts.

However, there is a unique example in which both wild deer and human beings share a relatively urbanized area in Japan. This example is from Nara prefecture, where more than 1,000 sika deer, which are designated as a protected species, utilise Nara Park and the neighbouring areas including Kasuga Shrine, a world heritage site. Although traffic accidents sometimes happen and agricultural/forestry damage occurs in neighbouring areas, there is no strong opposition to coexistence with sika deer in these areas. This may be one of the examples of successful sustainable coexistence with larger wildlife.

\section{REFERENCES}

[1] D. M. Theobald, "Placing exurban land-use change in a human modification framework," Frontiers in Ecology and the Environment, vol. 2, pp. 139-144, 2004.

[2] C. A. Bradley and S. Altizer, "Urbanization and the ecology of wildlife diseases," TRENDS in Ecology and Evolution, vol. 22, no. 2, pp. 95-102, 2006.

[3] M. Luniak, "Synurbization - Adaptation of animal wildlife to urban development," in Proc. 4th International Urban Wildlife Symposium, 2004, pp. 50-54.

[4] L. W. Adams, "Urban wildlife ecology and conservation: A brief history of the discipline," Urban Ecosystems, vol. 8, pp. 139-156, 2005.

[5] United Nations Department of Economic and Social Affairs, World Population Prospects, United Nations, 2003.

[6] Ministry of the Environment, 6th Baseline Survey on Conservation of Natural Environment, Tokyo, 2004.

[7] H. Kruuk, Hunter and Hunted: Relationships between Carnivores and People, Cambridge: Cambridge University Press, 2002.

[8] P. W. Bateman and P. A. Fleming, "Big city life: Carnivores in urban environments," Journal of Zoology, vol. 287, pp. 1-23, 2012.

[9] S. B. Magle, V. M. Hunt, M. Vernon, and K. R. Crooks, "Urban wildlife research: Past, present, and future," Biological Conservation, vol. 155 , pp. 23-32, 2012.

[10] S. C. Spackman and J. W. Hughes, “Assessment of minimum stream corridor width for biological conservation: Species richness and distribution along mid-order streams in Vermont, USA," Biological Conservation, vol. 71, pp. 325-332, 1995.

[11] E. W. Chapman and C. A. Ribic, "The impact of buffer strips and stream-side grazing on small mammals in southwestern Wisconsin," Agriculture Ecosystems and Environment, vol. 88, no. 1, pp. 49-59, 2002.
[12] H. Yamada and F. Nakamura, "Grassland and landscape ecology: Ecological functions of riparian buffers and effects of pasture development on riparian ecosystem," Grassland Science, vol. 48, no. 6, pp. 548-556, 2003.

[13] Ministry of the Environment. (2013). The number of hunting license holders. [Online]. Available: http://www.env.go.jp/nature/choju/docs/docs4/ menkyo.pdf

[14] D. Maillard and P. Fournier, "Effects of shooting with hounds on size of resting range of wild boar (Sus scrofa) groups in Mediterranean habitat," The Journal of Mountain Ecology, vol. 3, pp. 102-107, 1995.

[15] S. Takatsuki, "Sika deer and pasture grasses: A consideration on their significance for conservation ecology," Japanese Journal of Conservation Ecology, vol. 6, pp. 45-54, 2001.

[16] K. Kogure, Research on fox and raccoon dog, Tokyo: PHP Institute Office Int'l, Inc., 2002.

[17] H. R. Barcus, "Urban-rural migration in the USA: An analysis of residential satisfaction," Regional Studies, vol. 38, pp. 643-657, 2004.

[18] P. Howley, "Attitudes towards compact city living: Towards a greater understanding of residential behaviour," Land Use Policy, vol. 26, no. 3, pp. 792-798, 2009.

[19] G. Haughton and C. Hunter, Sustainable Cities, London: Routledge, 2003.

[20] O. Gillham, The Limitless City: A Primer on the Urban Sprawl Debate, Washington D.C.: Island Press, 2002.

[21] R. Rogers and A. Power, Cities for a Small Country, London: Faber and Faber Limited, 2000

[22] Y. Ohashi and K. Ishizaka, "Analysis of the effectiveness of the compact city policy: In the case of Aomori city," Journal of Architectural Planning AIJ, vol. 74, no. 635, pp. 177-183.

[23] G. B. Dantzig and T. L. Saaty, Compact City, A Plan for a Liveable Urban Environment, San Francisco: W. H. Freeman, 1973.

[24] H. Rudd, J. Vala, and V. Schaefer, "Importance of backyard habitat in a comprehensive biodiversity conservation strategy: A connectivity analysis of urban green spaces," Restoration Ecology, vol. 10, pp. 368-375, 2002.

[25] J. A. Hilty and A. M. Merenlender, "Use of riparian corridors and vineyards by mammalian predators in northern California," Conservation Biology, vol. 18, pp. 126-135, 2004.

[26] M. Hostetler and D. Drakeb, "Conservation subdivisions: A wildlife perspective," Landscape and Urban Planning, vol. 90, no. 3-4, pp. 95-101, 2009.

[27] L. R. Brown, Plan B: Rescuing a Planet under Stress and a Civilization in Trouble, New York: W. W. Norton \& Co., Inc., 2003.

[28] C. Y. Jim, "Green-space preservation and allocation for sustainable greening of compact cities," Cities, vol. 21, no. 4, pp. 311-320, 2004.

[29] MLIT. (2008). National Spatial Strategy. Tokyo: Ministry of Land, Infrastructure, Transport and Tourism. [Online]. Available: http://www.mlit.go.jp/common/000019219.pdf

[30] Agency for Cultural Affairs. (2013). Year book of Religion in Japan 2013. Tokyo: GYOSEI Corporation. [Online]. Available: http://www.bunka.go.jp/shukyouhoujin/nenkan/

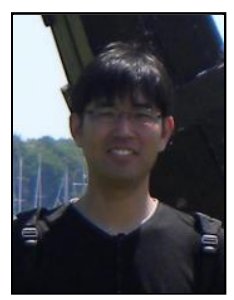

Yukichika Kawata was born in Yamaguch Prefecture, Japan. He received his Ph.D. from Kyoto University in 2004. His main research field is applied economics.

$\mathrm{He}$ is currently a faculty member at the Department of Animal and Food Hygiene, Obihiro University of Agriculture and Veterinary Medicine in Hokkaido. 